\title{
Uma análise da pobreza sob o enfoque multidimensional no Paraná
}

Marcela Ribeiro de Albuquerque ${ }^{1}$

Marina Silva da Cunha

Resumo: Este artigo tem como objetivo analisar a magnitude da pobreza no Paraná nos anos de 1995 e 2009, com base na perspectiva multidimensional de estudo da pobreza. Para tal foi obtido um índice de pobreza multidimensional domiciliar, a partir das informações da PNAD (Pesquisa Nacional por Amostra de Domicílios). Os resultados revelaram uma proporção significativa de pobres entre a população paranaense, de 27,9\%, em 1995, e 20,4\%, em 2009. Para as análises isoladas das regiões metropolitana, urbana e rural, verificou-se que a pobreza foi mais intensa na região rural. Portanto, embora os resultados do trabalho tenham apontado uma redução no grau de vulnerabilidade dos domicílios, ainda há uma parcela significativa da população em situação de pobreza.

Palavras-chave: pobreza multidimensional; índice de pobreza; Paraná.

JEL: I32.

\footnotetext{
1 Doutoranda do Programa de Pós-Graduação em Economia pela Universidade de Santa Catarina (UFSC). Professora assistente do Departamento de Economia da Universidade Estadual de Maringá (UEM). E-mail: marcela_ribeiro_albuquerque@yahoo.com.br 2 Pós-Doutora em Economia pela Universidade de Brasília (UnB). Professora associada da Universidade Estadual de Maringá (UEM). E-mail: mscunha@uem.br
} 


\title{
An analysis of poverty on the multidimensional approach in Paraná
}

\begin{abstract}
This article intents to analyze the magnitude of poverty in Paraná in 1995 and 2009, on the basis of the multidimensional approach to the study of poverty. For that, it was obtained the multidimensional housewold poverty rate, from the PNAD (Pesquisa Nacional por Amostra de Domicílios). The results showed a significant proportion of poor people among the paranaense population, $27,9 \%$ in 1995 and 20,4\% in 2009. For the isolated analyses of the metropolitan, urban and rural regions the poverty was most intense in the rural region. Therefore, although the results of the article have shown a reduction in the vulnerability of households degree, there is still a significant part of the population in poverty.
\end{abstract}

Key-words: multidimensional poverty; index of household poverty; Paraná.

JEL: I32.

\section{Introdução}

A discussão da temática pobreza, em especial no meio acadêmico, com o surgimento de novas contribuições conceituais e metodológicas para sua quantificação, tornou-se essencial no que concerne ao direcionamento de políticas públicas que visem ao seu combate, por meio do entendimento de que a questão da pobreza está diretamente relacionada ao desenvolvimento econômico. Isto se deve às dificuldades inerentes ao processo de enfrentamento desse fenômeno, o qual é apontado pelos organismos internacionais como um dos principais problemas de um sistema econômico e que acaba por limitar significativamente o processo de desenvolvimento dos países.

Durante muitos anos, o conceito predominante de pobreza consistia simplesmente na ausência de renda. Tal conceito já não se adequa mais ao atual cenário político-econômico e social dos países. Demandam-se outras formas de compreensão das situações de pobreza em que as economias incorrem, sendo que muitos estudos internacionais e nacionais começaram a ser desenvolvidos, construindo novos argumentos, bem como incluindo novas abordagens na análise ${ }^{1}$.

O presente artigo busca apresentar uma abordagem multidimensional para mensurar a pobreza no Estado do Paraná nos anos de 1995 e 2009. Assim, contribui para enfatizar a necessidade de não limitar a compreensão da pobreza à ausência de renda, na medida em que expande o entendimento sobre a temática ao expor a abordagem multidimensional da pobreza no Paraná.

1 Ver Comim e Bagolin (2002); Fusco (2003); Kageyama e Hoffmann (2006); Barros, Carvalho e Franco (2003) e Neder (2008). 
O estudo está dividido em cinco seções, incluindo a introdução. Na seção 2 é feita uma concisa revisão da definição, da mensuração e das evidências sobre a pobreza. A seção seguinte apresenta a metodologia empregada, em que é construído um indicador multidimensional para a pobreza no Paraná. Na seção 4, são discutidos os resultados do indicador proposto. Finalmente, na última seção, destacam-se as principais conclusões do estudo.

\section{Concepções, mensuração e evidências sobre a pobreza}

O enfoque dominante na produção acadêmica sobre a temática pobreza aborda a partir da perspectiva monetária (em ter ou não acesso aos recursos monetários), focalizando a renda e o consumo de indivíduos e domicílios como informação básica tanto para a concepção quanto para a mensuração da pobreza. Daí considera-se que são pobres aqueles indivíduos que não dispõem de um nível de renda suficiente para satisfazer às necessidades de sobrevivência.

Para Sen (1976), a mensuração da pobreza envolve duas tarefas, são elas: identificar os indivíduos ou famílias pobres entre a população total e construir um índice de pobreza usando a informação disponível. O procedimento mais comum para realizar isso é simplesmente contar o número de pobres e verificar o percentual da população total que pertence a essa categoria. Assim, a identificação dos pobres pode ser feita por meio do método da renda, que estabelece um determinado nível de renda abaixo do qual as pessoas são classificadas como pobres. Esse nível de renda deve ser definido como o suficiente para que as pessoas cubram as suas necessidades básicas. Tal método de mensuração é chamado de critério da linha de pobreza, que permite a definição de medidas de intensidade da pobreza, entendidas como distâncias numéricas da situação de cada indivíduo em relação à pobreza.

Além da linha de pobreza, é usual na literatura sobre o tema utilizar linhas de extrema pobreza ou de indigência, que seria uma proporção da linha de pobreza. Entre os critérios de definição dessas linhas, são utilizados o rendimento pessoal em dólar, rendimento per capita familiar ou domiciliar com base no salário mínimo, consumo de calorias necessárias para a subsistência (kcal) ou cesta básica convertida em renda. ${ }^{2}$

Para Rocha (2003), embora as linhas de pobreza e indigência sejam o enfoque mais considerado no discurso e nas práticas de mensuração da pobreza, há fragilidades e limitações. Uma das fragilidades reside na impossibilidade de definir um nível mínimo abaixo do qual os indivíduos encontram-se ameaçados em sua sobrevivência. Existe esse nível, mas não se pode desconsiderar que ele, mesmo estabelecido como ponto de demarcação, é sempre relativo, fruto

2 Para maiores detalhes sobre o cálculo das linhas de pobreza, ver Hoffmann (1998). 
de uma convenção. Assim, a principal crítica que se faz à construção da linha de pobreza e indigência é o fato de não retratarem todas as dimensões da pobreza, uma vez que o nível de bem-estar dos indivíduos é determinado por um conjunto complexo de fatores sociais e não somente pela renda.

Hoffmann (1998) argumenta que a renda é uma medida bastante imperfeita das condições de vida das pessoas e das famílias, embora ainda seja a melhor medida isolada dessas condições. Dado certo nível de renda para uma família, as condições de saúde de seus membros, ou ainda o nível educacional, por exemplo, podem fazer que ela esteja ou não em condições de pobreza.

Abordagens distintas da perspectiva monetária surgem no meio acadêmico a partir das críticas, da concepção existente de que o enfoque da renda não é suficiente para dimensionar a situação de pobreza, buscando incluir em suas análises as variáveis não monetárias que influenciam a situação de pobreza. Desse modo, parte-se de uma perspectiva absoluta de pobreza em que pobre é aquele que tem menos do que um mínimo objetivamente definido, para uma perspectiva relativa, em que o pobre é que tem menos do que os outros na sociedade.

Para tanto, conforme Rocha (2003), a princípio, tem-se um maior destaque para a perspectiva das necessidades básicas, especialmente nas décadas de 1970 e 1980, a qual tem como essência a identificação de déficits, privações e níveis de carência que condicionam a pobreza. Esse enfoque sustenta que são pobres as pessoas que não têm suas necessidades básicas atendidas, cujo consumo de uma cesta de bens e serviços não atinge o mínimo considerado necessário para subsistência. Atingir o mínimo considerado necessário seria equivalente a não dispor de meios para o acesso aos serviços básicos como educação, saúde, habitação, entre outros (apesar de não haver um padrão na identificação das variáveis necessárias). Portanto, a abordagem das necessidades básicas insere e questiona a relatividade presente na caracterização e na mensuração da pobreza por considerar que as necessidades são relativas a tempos e lugares, regiões e referidas aos padrões vigentes em cada sociedade.

Assim, a partir do fim da década de 1970 houve uma evolução das concepções de pobreza para além da carência de renda, na direção de conceitos mais abrangentes, tais como: desigualdade, exclusão social e vulnerabilidade. A desigualdade proveniente da estrutura econômica continua sendo a primeira razão da pobreza. Desigualdade de renda, desigualdade de acesso, desigualdade de meios, desigualdade na detenção de ativos são exemplos.

Um grande expoente na análise da pobreza sob o enfoque além da carência de renda é o economista Amartya Sen, Prêmio Nobel de Economia, pelas suas contribuições nos estudos acerca da miséria, da pobreza e do bem-estar social. Os trabalhos desse autor se constituem no ponto de partida da formulação da abordagem das capacitações ou das capacidades. 
Nessa abordagem das capacidades, são considerados pobres os indivíduos que são desprovidos de capacidades básicas para atuarem em sociedade, bem como de oportunidades para alcançar níveis aceitáveis de realizações e conquistas. Logo, tal enfoque viabiliza o reconhecimento, a inclusão de outras variáveis tão determinantes para a situação de pobreza quanto a renda, que busca inserir a privação de capacitações. Para Sen (2000), a pobreza está relacionada à privação de liberdade das pessoas (política, facilidades econômicas, oportunidades sociais) de poderem escolher uma vida mais satisfatória que lhes proporcione maior bem-estar.

Embora alguns autores se esforcem para destacar as semelhanças entre o enfoque monetário e o das capacidades, há uma mudança de foco. $\mathrm{Na}$ abordagem monetária, a ênfase reside nos recursos privados aos quais os indivíduos têm acesso, enquanto no enfoque das capacidades o importante é examinar a vida que os indivíduos podem ter. Por essa ótica, é importante perceber se existem possibilidades de os membros de uma determinada sociedade terem uma vida digna.

Entretanto, existem críticas direcionadas à abordagem multidimensional da pobreza, as quais apresentam cunho quantitativo e qualitativo (Salama e Destremau, 1999). A primeira argumenta que a avaliação empírica da pobreza multidimensionada é dificultada pela necessidade de ponderação de múltiplos conceitos de pobreza em um único indicador. Além disso, a própria definição de pobreza multidimensional para diferentes sociedades encontra dificuldades nos estudos empíricos, devido às dificuldades de operacionalização, já que costumam envolver aspectos não observáveis e mensuráveis quantitativamente. A segunda, de cunho qualitativo expõe que a abordagem multidimensional da pobreza pode criar uma confusão entre as suas causas e a pobreza efetiva, referente à renda, o que pode levar a uma subestimação do papel da renda sobre esse fenômeno.

Portanto, a pobreza deve ser vista como privação de capacidades básicas em vez de meramente como baixo nível de renda, que é o critério tradicional de identificação da pobreza. A abordagem da pobreza como carência de capacidades não refuta a ideia de que a renda pode ser uma razão primordial da privação de capacidades do indivíduo, pois as perspectivas da pobreza sob o enfoque da renda e das capacitações são conexas, ou seja, ganhos de capacitação proporcionam incremento da renda que, por sua vez, contribui para a redução da pobreza por renda.

No Brasil, a temática da pobreza sob o enfoque multidimensional vem sendo aplicada em trabalhos e análises empíricas. Entre estes, podem-se citar Barros et al. (2003); Lopes et al. (2005); Kageyama e Hoffmann (2006); Neder (2008); Nóbrega (2008) e Munhoz (2009). 
Em seu trabalho, Barros et al. (2003) utilizaram a abordagem multidimensional - seguindo a conceituação de pobreza sob o enfoque das necessidades básicas e das capacitações - para formular um índice escalar multidimensional de pobreza familiar baseado nas informações da PNAD. Elaboraram um Índice de Desenvolvimento da Família com 6 dimensões, 26 componentes e 48 indicadores. Uma das vantagens de tal indicador é a possibilidade de desagregar os dados e, assim, poder mensurar a pobreza para grupos demográficos distintos.

Lopes et al. (2005) trataram a pobreza de forma multidimensional no Brasil e em Minas Gerais, incorporando o enfoque das capacidades de Amartya Sen. O banco de dados foi composto por informações do Censo demográfico de 2000 e do Atlas da Criminalidade de Belo Horizonte. A metodologia adotada enfatizou o grau de disseminação de alguns atributos básicos de bem-estar entre as famílias, a saber: renda domiciliar total líquida; tamanho da família e dimensões da residência; problemas ambientais relacionados com crime e status ocupacional; acesso a banheiro e aquecimento residencial; tipologia econômica do domicílio e status da atividade principal, nível educacional e atividade principal da pessoa de referência. Os resultados do estudo confirmam a hipótese de que o índice de pobreza baseado na renda não é suficiente para identificar a extensão da pobreza em uma determinada população.

Em seu trabalho, Kageyama e Hoffmann (2006) analisaram a pobreza no Brasil sob o enfoque multidimensional no período de 1992 a 2004. Para mensurar a pobreza, eles combinaram a medida tradicional baseada na renda com aspectos relativos ao bem-estar. Com a utilização dos microdados da Pesquisa Nacional por Amostra de Domicílios (PNAD) para o período em questão, adotaram a linha de pobreza de meio salário mínimo per capita, atualizados para valores em reais de 2005. Classificaram os pobres em três substratos: i) insuficiência de renda; ii) falta de acesso a pelo menos dois de três quesitos básicos (acesso à água canalizada, banheiro e luz elétrica); iii) baixa renda combinada com a ausência de acesso aos três equipamentos básicos. Os resultados apontaram que a pobreza do primeiro substrato tendeu a apresentar variações cíclicas (em acordo com a conjuntura econômica) e que a pobreza dos demais substratos eram menos suscetíveis aos ciclos econômicos, pois trata-se de questões estruturais da economia brasileira, ou seja, demanda-se o longo prazo como o desenvolvimento regional e os investimentos em infra estrutura.

Neder (2008) desenvolveu um estudo em que emprega o enfoque multidimensional ao analisar o nível de pobreza rural. Para tanto, construiu um índice de pobreza multivariada, contemplando as condições domiciliares, de saneamento, de mercado de trabalho e de educação. Os resultados obtidos para os anos de 1995 e 2004, ao ser empregada a metodologia multivariada, foram comparados a uma metodologia que considera apenas a renda (unidimensional). Constatou-se que os indicadores de pobreza multivariada 
possuem um ordenamento bastante distinto para os Estados do Brasil, quando comparados com o ordenamento do indicador de pobreza baseado na insuficiência de renda, em especial para o ano de 2004. Com isso, o autor recomenda a continuidade dos estudos com a abordagem multidimensional para o direcionamento de políticas públicas que amenizem a situação de pobreza no meio rural.

Nóbrega (2008) realizou um estudo em que verificou a contribuição da Análise Exploratória de Dados Espaciais para a identificação de espaços de pobreza nos estados do Paraná e Sergipe, por considerar que são estados com situações de ordem econômica bem distintas. Para tal, calculou diferentes indicadores de pobreza - linha monetária de pobreza e IPH-M - utilizando os microdados do Censo 2000, os quais foram aplicados aos municípios de ambos os estados. O método da análise exploratória de dados espaciais permitiu a revelação de clusters regionais de pobreza em cada estado, o que tornou possível a identificação de espaços de pobreza. A conclusão do autor foi de que a pobreza é inversamente associada à diversidade local da economia, em que a maior complexidade da economia paranaense e sua maior relação com a economia nacional e internacional afastou a pobreza para lugares onde a divisão do trabalho é menor. Ademais para ambos os estados, a pobreza está localizada em zonas de não influência das grandes cidades.

Em seu estudo, Munhoz (2009) utilizou os microdados do censo do IBGE (2000) dos municípios do Estado do Paraná para mensurar e mapear a pobreza neste estado. Para tanto, escolheu os indicadores: índice Firjam de desenvolvimento econômico; índice de pobreza humana municipal de Rolim (2006) e linha de indigência de Rocha (2003). A linha de pobreza optada foi a do PNUD/IBGE de 1/2 salário mínimo. A análise estatística multivariada da pobreza foi realizada por uma regressão de mínimos quadrados. Os resultados mostraram que o indicador proposto mostra que os municípios com os piores percentuais educacionais também apresentam os piores índices de pobreza do Estado do Paraná.

\section{Metodologia e construção do induscador de pobreza multidimensional para o Paraná}

$\mathrm{O}$ índice de pobreza multidimensional domiciliar fora obtido a partir das informações da PNAD de 1995 e 2009. Neste trabalho, a unidade de análise é o domicílio e, considerando os domicílios com todas as informações disponíveis, contou-se com 5.483 e 6.361 domicílios nas amostras extraídas da PNAD, respectivamente, e 2.306.221 e 3.437.999 domicílios nas populações estimadas considerando os pesos. 
De acordo com Barros et al. (2003), existem inúmeras estratégias para a construção de indicadores sintéticos de pobreza ${ }^{3}$, em que a maneira mais simples seria obter o indicador sintético a partir de uma série de indicadores.

Neste trabalho, foram consideradas seis dimensões na elaboração de um indicador multidimensional, conforme o Quadro 1. Nota-se, além das 6 dimensões, 18 componentes e 21 indicadores ou variáveis. Elas foram escolhidas com base na revisão da literatura acerca da temática da pobreza, tanto sob o enfoque das necessidades básicas quanto das capacidades.

QUADRO 1. DESCRIÇÃO DOS COMPONENTES E VARIÁVEIS DO INDICADOR MULTIDIMENSIONAL DE POBREZA

\begin{tabular}{|c|c|}
\hline Componentes & Variáveis \\
\hline \multicolumn{2}{|c|}{ Dimensão 1: Condições habitacionais } \\
\hline Abrigabilidade & $\begin{array}{l}\text { H1: Material de construção não é permanente } \\
\text { H2: Material de cobertura não permanente }\end{array}$ \\
\hline Propriedade & H3: Domicílio não é próprio \\
\hline Energia elétrica & $H_{4}$ : Sem acesso à energia elétrica \\
\hline Déficit habitacional & $H_{5}:$ N. ${ }^{\circ}$ de moradores por cômodo $>3$ \\
\hline \multicolumn{2}{|l|}{ Dimensão 2: Saneamento } \\
\hline Esgoto sanitário & S1: Esgotamento sanitário inadequado \\
\hline Abastecimento de água & $S 2$ : Acesso inadequado à água \\
\hline Coleta de lixo & $S_{3}$ : Lixo não é coletado \\
\hline Condição sanitária & S4: Não possui banheiro no domicílio \\
\hline \multicolumn{2}{|l|}{ Dimensão 3: Educação } \\
\hline Analfabeto & E1: Presença de adulto analfabeto \\
\hline Acesso à escola & E2: Presença de criança fora da escola \\
\hline Escolaridade & E3: Ausência de adulto com ens. fundamental \\
\hline & E4: Ausência de adulto com ens. médio \\
\hline & E5: Ausência de adulto com ens. superior \\
\hline Progresso escolar & $\begin{array}{l}\text { E6: Presença de criança de até } 14 \text { anos com } \\
\text { ao menos } 2 \text { anos de atraso }\end{array}$ \\
\hline \multicolumn{2}{|l|}{ Dimensão 4: Trabalho } \\
\hline Qualidade & T1: Ausência de ocupado no setor formal \\
\hline Disponibilidade & T2: Menos da metade dos membros em idade ativa \\
\hline Trabalho precoce & $T_{3}$ : Presença de trabalho infantil \\
\hline \multicolumn{2}{|l|}{ Dimensão 5: Renda } \\
\hline Extrema pobreza & $R 1$ : Renda domiciliar per capita inferior à $\mathrm{LP}^{*}$ \\
\hline Pobreza & R2: Renda domiciliar per capita inferior à LP* \\
\hline \multicolumn{2}{|l|}{ Dimensão 6: Demografia } \\
\hline Razão de dependentes & $D 1:$ N. ${ }^{\circ}$ de crianças e idosos $>$ do que o de adultos \\
\hline
\end{tabular}

FONTE: elaborado a partir de dados da PNAD. *LP = Linha de Pobreza.

3 Ver Chakravarty, Mukherjee e Ranade (1998), Bourguignon e Chakravarty (1999, 2002a e b), Tsui (2002), Atkinson (2003) e Duclos, Sahn e Younger (2003). 
Em relação à escolha dos pesos, esta se dá de forma simétrica ao atribuir pesos iguais a todas as dimensões e seus respectivos componentes. A justificativa para conferir pesos iguais é a do desconhecimento das preferências da população analisada. Portanto, tem-se o mesmo peso para: a) todos os indicadores de cada componente de uma mesma dimensão; b) todos os componentes de uma mesma dimensão; c) cada uma das seis dimensões que compõem o índice.

Às variáveis de um mesmo componente são dados pesos idênticos. A todos os componentes de uma mesma dimensão também se atribuiu pesos idênticos e inclusive as dimensões receberam os mesmos pesos. Porém, como variam tanto o número de componentes por dimensão como o número de variáveis por componente, o peso atribuído às variáveis de diferentes componentes nem sempre é o mesmo. A ponderação, entretanto, é padronizada de tal forma que o grau de pobreza de cada domicílio pudesse variar entre o (para aqueles domicílios sem qualquer traço de pobreza) e 100 (para os domicílios absolutamente pobres).

Para a constituição do indicador sintético multidimensional, é necessária sua agregabilidade, ou seja, o indicador sintético de cada componente, $S_{j k}$, é a média aritmética dos indicadores utilizados para representá-lo. Da mesma forma, o indicador sintético de cada dimensão, $S_{k}$, é a média aritmética dos indicadores sintéticos de seus componentes. Por fim, o indicador sintético global, $S$, é a média aritmética dos indicadores sintéticos das seis dimensões que o compõem.

$$
S=\frac{1}{6} \sum_{k=1}^{6}\left(\frac{1}{m_{k}} \sum_{j=1}^{m_{k}}\left(\frac{1}{n_{j_{k}}} \sum_{i=1}^{n_{j k}} B_{j_{k i}}\right)\right)
$$

em que $B_{j k i}$ denota o $i$-ésimo indicador básico do $j$-ésimo componente da $k$-ésima dimensão; $m_{\mathrm{k}} \mathrm{o}$ número de componentes da $k$-ésima dimensão e $n_{j k}$ o número de indicadores do $j$-ésimo componente da $k$-ésima dimensão.

Como se pode observar no Quadro I, mesmo tratando-se de uma abordagem multidimensional com base nas necessidades básicas e nas capacitações, são incluídas as variáveis proporções de domicílios abaixo das linhas de pobreza e extrema pobreza ou indigência, na dimensão renda, as quais foram obtidas junto ao IPEADATA (2010). ${ }^{4}$

4 As linhas de pobreza utilizadas para o Paraná, em 1995, foram, respectivamente, de $\mathrm{R} \$ 81,13$ para a Região Metropolitana de Curitiba, $\mathrm{R} \$ 77,40$ para a área urbana e $\mathrm{R} \$ 70,46$ para a zona rural, enquanto as linhas de extrema pobreza ou indigência foram de: $\mathrm{R} \$ 40,57$ para a Região Metropolitana de Curitiba, $\mathrm{R} \$ 38,70$ para a área urbana e $\mathrm{R} \$ 35,23$ para a zona rural. Já em 2009, foram respectivamente, de $\mathrm{R} \$ 206,46$ para a Região Metropolitana de Curitiba, $\mathrm{R} \$ 196,95$ para a área urbana e $\mathrm{R} \$ 179,29$ para a zona rural; enquanto as linhas de extrema pobreza ou indigência foram de: $\mathrm{R} \$ 103,23$ para a Região Metropolitana de Curitiba, $\mathrm{R} \$ 98,48$ para a área urbana e $\mathrm{R} \$ 89,65$ para a zona rural. As informações estão em valores correntes para os anos de 1995 e 2009. 


\section{Aplicação e análise da pobreza no Paraná a partir de um indicador multidimensional}

A Tabela 1 apresenta os resultados do indicador multidimensional no Paraná, obtido com a metodologia explicitada. Os resultados do trabalho sugerem uma redução de 26,69\% na pobreza no Estado do Paraná de 1995 para 2009, de 27,88\% para 20,44\%, segundo a metodologia adotada. Os maiores indicadores de pobreza no Paraná, em 1995, concentram-se nas dimensões de educação e demografia, com uma proporção de, respectivamente 32,9\% e 44,8\% domicílios em condições inadequadas. Já no ano de 2009, os maiores indicadores estão nas dimensões trabalho e demografia, com proporções de $24,4 \%$ e $36,6 \%$, respectivamente.

A dimensão "moradia" expressa, em geral, as condições habitacionais dos domicílios analisados. Tem como maior déficit, no ano de 1995, o componente propriedade, que corresponde à variável "domicílio próprio", em que 29,6\% dos domicílios no Estado não são próprios. Em 2009, esse indicador evidencia que não houve significativa melhora nessa variável, já que a proporção nesse ano é de $28,5 \%$.

O componente abrigabilidade se mostra significativo em 1995, indicando que em 24,1\% dos domicílios o material de construção e de cobertura do telhado não são permanentes. Assim, trata-se de materiais que tanto para as paredes quanto para a cobertura são não duráveis, podendo ser de zinco, madeira aproveitada, palha ou outro material não-durável. Em 2009, esse indicador se reduz para $13,6 \%$.

Acerca dessa dimensão, exemplos de programas com o objetivo de diminuir tais vulnerabilidades no Estado são o "Casa da Família", o "Vila Rural" e o "Direito de Morar e Casa da Família". O Primeiro foi instituído no primeiro governo Requião (1992-1995), em que houve a construção de casas com prestações a preços populares. O programa "Vila Rural" foi desenvolvido em 1995 em parceria entre prefeituras e diversos órgãos do governo estadual, executado pela Companhia de Habitação do Paraná (COHAPAR) para a construção de moradias para trabalhadores rurais volantes, os boias-frias. Por fim, houve o projeto "Direito de Morar e Casa da Família", lançado em 2003, coordenado pela COHAPAR em parceria com o governo federal e prefeituras locais, destinado à regularização de favelas e áreas invadidas e às famílias com renda mensal média de até três salários mínimos.

No Paraná, segundo os dados do Ipardes (2010), em 2007, a carência por moradias (déficit habitacional) era de 166.862 unidades, e na Região Metropolitana de Curitiba era de 53.765 unidades. Esses dados consideram as habitações improvisadas, rústicas, a cohabitação familiar e cômodos cedidos, alugados ou cohabitação disfarçados. 
Em relação à dimensão "saneamento" do indicador multidimensional de pobreza, as situações mais vulneráveis, tanto em 1995 quanto em 2009, são o esgotamento sanitário e a coleta de lixo. Em 1995, 66\% dos domicílios no Paraná não possuíam esgotamento sanitário adequado, e 21,6\% dos domicílios eram desprovidos de coleta de lixo. Já para 2009, essas variáveis apresentaram a magnitude de $33,7 \%$ e $9,2 \%$, respectivamente, o que representou uma queda na ordem de $49 \%$ e 57,3\% no período de 1995 a 2009.

TABELA 1. INDICADORES MULTIDIMENSIONAIS DA POBREZA NO PARANÁ

\begin{tabular}{|c|c|c|c|}
\hline Descrição & 1995 & 2009 & Variação (\%) \\
\hline Estado do Paraná & 0,2788 & 0,2044 & $-26,69$ \\
\hline Dimensão 1: Condições Habitacionais & 0,1887 & 0,1238 & $-34,40$ \\
\hline Abrigabilidade & 0,2413 & 0,1357 & $-43,76$ \\
\hline Propriedade & 0,2962 & 0,2850 & $-3,76$ \\
\hline Energia elétrica & 0,0426 & 0,0044 & $-89,62$ \\
\hline Déficit habitacional & 0,1746 & 0,0699 & $-59,95$ \\
\hline Dimensão 2: Saneamento & 0,2521 & 0,1129 & $-55,20$ \\
\hline Esgotamento sanitário & 0,6609 & 0,3371 & $-48,99$ \\
\hline Abastecimento de água & 0,0910 & 0,0128 & $-85,98$ \\
\hline Coleta de lixo & 0,2158 & 0,0922 & $-57,27$ \\
\hline Condição sanitária & 0,0408 & 0,0098 & $-76,07$ \\
\hline Dimensão 3: Educação & 0,3289 & 0,2407 & $-26,81$ \\
\hline Analfabetismo & 0,2292 & 0,1327 & $-42,11$ \\
\hline Acesso à escola & 0,0565 & 0,0085 & $-84,97$ \\
\hline Escolaridade & 0,8303 & 0,7268 & $-12,47$ \\
\hline Progresso escolar & 0,1994 & 0,0948 & $-52,46$ \\
\hline Dimensão 4: Trabalho & 0,2677 & 0,2435 & $-9,02$ \\
\hline Qualidade & 0,6231 & 0,5197 & $-16,60$ \\
\hline Disponibilidade & 0,1639 & 0,2090 & 27,46 \\
\hline Trabalho precoce & 0,0160 & 0,0019 & $-87,86$ \\
\hline Dimensão 5: Renda & 0,1879 & 0,1393 & $-25,85$ \\
\hline Extrema pobreza & 0,1082 & 0,0352 & $-67,49$ \\
\hline Pobreza & 0,2869 & 0,1108 & $-61,40$ \\
\hline Dimensão 6: Demografia & 0,4476 & 0,3661 & $-18,20$ \\
\hline Razão de dependentes & 0,4476 & 0,3661 & $-18,20$ \\
\hline
\end{tabular}

FONTE: elaborado a partir das informações da PNAD. 
Conforme os dados da RIPSA (2010), a proporção da população servida por esgoto no Estado do Paraná, em 1995, era de 38,82\% (equivalente a 3.460.337 habitantes), e na Região Metropolitana era 60,80\% (equivalente a 1.415.682 habitantes). Já em 2008 (últimos dados disponíveis), o percentual no Estado fora $71,84 \%$ (equivalente a 7.604.866 habitantes), e na Região Metropolitana, $88,44 \%$ (2.846.859 habitantes).

Por outro lado, apesar do quadro positivo no que concerne à redução dessas vulnerabilidades no período em análise, tal situação indica um sério problema quanto à saúde preventiva, que fica altamente comprometida diante desse cenário. Fazem-se necessários maiores investimentos públicos na concessão desses serviços básicos e essenciais à população, para que esta não incorra em doenças oriundas dessas vulnerabilidades.

A terceira dimensão, "educação" apresentou grandes deficiências, especialmente para a escolaridade dos adultos nos domicílios de 1995 e 2009. Em 1995, em 83\% dos domicílios pesquisados, havia adultos residentes que não possuíam ensino fundamental, ensino médio e/ou ensino superior. Esses resultados se alteraram positivamente em 2009, quando 72,7\% dos domicílios pesquisados sofrem tais vulnerabilidades. Essas dimensões observadas em 2009 expressam uma queda de 12,5\% na proporção de domicílios em que havia adultos que não possuíam ensino fundamental, médio e/ou superior. Uma possível explicação seria a fraca política educacional historicamente empregada no Brasil e as condições de profunda desigualdade na distribuição de renda, em que muitos adultos em idade escolar tiveram de interromper os estudos para trabalhar e buscar sua própria sobrevivência e de suas famílias.

Entretanto, há de se destacar a variável "criança fora da escola”, cuja proporção para o ano de 1995 foi de 5,7\% nos domicílios Paranaenses analisados, e em 2009 praticamente se erradicou essa vulnerabilidade, ao considerar que em $0,9 \%$ dos domicílios existem crianças fora da escola. Particularmente no Estado do Paraná, a temática da Educação Básica foi prioridade durante as décadas de 1980 e de 1990. Nessa última década, prevaleceu a tese da "centralidade da Educação Básica", na qual educação era entendida como um instrumento de viabilização do crescimento econômico, integração dos indivíduos ao mercado de trabalho (e assim a criação de potenciais consumidores), bem como mediadora do combate à pobreza.

Ações como "Amigos da Escola”, "Bolsa Escola", "Vale Gás” etc., desencadeadas nacionalmente, assim como os projetos "Paraná: Construindo a Escola Cidadã", "Correção de Fluxo", "Vale Ensinar", "Da Rua para Escola”, "Ciclo Básico de Alfabetização", entre outras realizadas no Estado, contribuem nesse processo. Os desdobramentos que tiveram o projeto "Paraná: Construindo a Escola Cidadã", 1992, e o documento "Inovando nas Escolas do Paraná", 1994, também podem ser destacados (Figueiredo, 2003). 
Ademais, ainda pode ser citado, na década de 2000, o programa Bolsa Família, do qual uma das exigências para os beneficiários é a manutenção de seus filhos em idade escolar na escola.

A dimensão "trabalho" reflete a estrutura do mercado de trabalho nacional, especialmente no resultado para a ocupação no setor formal da economia, em que 62,3\% dos domicílios pesquisados no Paraná, em 1995, apresentavam empregados no setor informal ou ainda desempregados. Em 2009, essa proporção se reduz para 52\% - apesar da variação negativa de $16,5 \%$ de 1995 para 2009. Esse indicador é preocupante, pois expressa que em parte significativa desses domicílios ainda há indivíduos desamparados pelas políticas de seguridade social.

Por outro lado, alguns programas sociais foram implementados com o objetivo de ampliar a participação dos residentes Paranaenses no mercado de trabalho. O programa "Bom Emprego" tinha como finalidade a geração de um maior número de empregos diretos na zona rural, à medida que industrializava as matérias-primas nos locais onde elas eram produzidas, e com isso reduzia o superpovoamento das grandes cidades, bem como por meio de investimentos e ampliação da produção no setor agroindustrial, via adiantamento do recolhimento de ICMS por até oito anos, por exemplo.

Foi criado também o programa "Bom Emprego Industrial”, que visava a apoiar a implantação e a expansão de estabelecimentos industriais, criando condições para a modernização tecnológica e o incremento do emprego. De acordo com Resende (2007: 69), “[...] a sua concepção estrutural preservava os princípios básicos da universalidade de acesso, da automaticidade de enquadramento, da redução dos custos financeiros e da descentralização de investimentos [...]”. Outro programa foi o "Primeiro Emprego Residência Técnica”, direcionado ao ingresso de jovens recém-qualificados no mercado de trabalho, através de incentivos fiscais às empresas que ofertassem o primeiro emprego a eles por um período de seis meses a um ano. ${ }^{5}$

Outra variável dessa dimensão se refere à presença de trabalho infantil, que merece destaque no ano de 2009, quando os resultados indicam que as crianças nos domicílios pesquisados no Estado não se encontravam exercendo atividades laborais. Nesse caso, pode ser citado o Programa de Erradicação do Trabalho Infantil (PETI), do Governo Federal, aliado a outras garantias constitucionais empregadas por meio do Estatuto da Criança e do Adolescente ${ }^{6}$.

5 Conforme Ipardes (2010), de 2001 para 2009, o número total de empregos formais no Paraná aumentou em 916.133, passando de 1.721.656 empregos formais, em 2001, para 2.637.789, em 2009, um incremento de 53,2\%. 6 Art. 6o. É proibido qualquer trabalho a menores de quatorze anos de idade, salvo na condição de aprendiz. (Estatuto da Criança e do Adolescente, 1990) 
As variáveis pertencentes à dimensão "renda” são os domicílios que se encontram abaixo da linha de extrema pobreza e pobreza. Os dados de 1995 indicam que a variável renda domiciliar per capita inferior à linha de pobreza apresentou uma proporção de 28,7\%, enquanto em 2009 essa proporção se reduziu para significativos $61,7 \%$, passando para $11 \%$ dos domicílios analisados em situação de pobreza. No caso da extrema pobreza, a redução foi de $10,82 \%$ para $3,52 \%$.

Portanto, ao incorporar outras variáveis para mensurar a pobreza, tem-se que enquanto o indicador multidimensional sugere 20,44\% de domicílios em situação de vulnerabilidade no Paraná, em 2009, apenas 11\% dos domicílios estão abaixo da linha de pobreza.

Vale destacar que a proporção de domicílios pobres e extremamente pobres obtidos pelo Instituto de Pesquisa Econômica e Aplicada (IPEA), a partir das PNADs, são similares aos estimados neste trabalho, corroborando os resultados apresentados. No caso da extrema pobreza, os percentuais obtidos pelo IPEA foram iguais a 9,7\% e 3,1\%, respectivamente, em 1995 e 2009, e iguais a $25,6 \%$ e 9,5\%, no caso da pobreza. ${ }^{7}$

A variável pertencente à dimensão “demografia” do indicador multidimensional de pobreza evidencia que 44,8\% dos domicílios da amostra, em 1995, possuíam o número de dependentes maiores do que os não dependentes, e em 2009 essa proporção caiu para 36,6\%. Esse fato permite uma diminuição do grau de vulnerabilidade do domicílio, uma vez que uma maior proporção de adultos pode contribuir mais para o aumento da renda per capita domiciliar.

Os resultados apresentados estão sintetizados no Gráfico 1, que traz o indicador multidimensional de pobreza calculado para o Paraná nos anos de 1995 e 2009, em cada dimensão. Notadamente a dimensão demografia se constitui na maior vulnerabilidade do Estado, tanto em 1995 quanto em 2009, seguida pela educação e pelo trabalho. O pior desempenho entre 1995 e 2009 deu-se na dimensão trabalho, em que a mudança no que tange à redução de tal vulnerabilidade foi de apenas 9\%. Neste sentido, o melhor desempenho foi o da dimensão saneamento, em que ocorreu uma queda na ordem de $55 \%$.

Após a descrição dos resultados obtidos a partir do emprego do indicador multidimensional de pobreza para o Paraná nos anos de 1995 e 2009, com destaque para as variáveis que apresentaram proporcionalmente uma maior queda, indicando redução destas vulnerabilidades, faz-se necessário destacar também o processo contrário, ou seja, dentre as variáveis estudadas, qual ou quais delas apresentaram um aumento da vulnerabilidade para o período em questão.

7 Ver também os resultados obtidos pelo IETS (2010). 
GRÁFICO 1. INDICADORES MULTIDIMENSIONAIS DE POBREZA

NO PARANÁ PARA AS DIMENSÕES MORADIA, SANEAMENTO,

EDUCAÇÃO, TRABALHO, RENDA E DEMOGRAFIA, EM 1995 E 2009

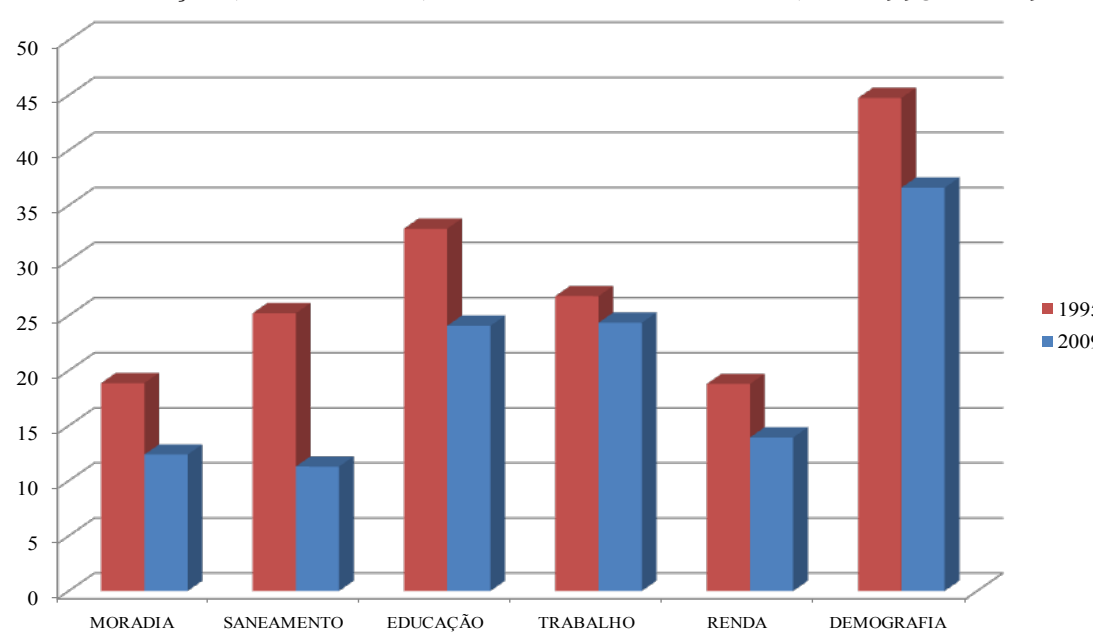

FONTE: elaborado a partir das informações da PNAD.

Assim, considerando todas as variáveis estudadas para o período de 1995 a 2009, tem-se que a variável "menos da metade dos membros em idade ativa se encontram ocupados", pertencente à dimensão trabalho, aumentou em $27,5 \%$, o que se traduz em uma proporção de $21 \%$, em 2009, frente aos 16,4\% de 1995. Esse resultado é considerado negativo, por ter aumentado o grau de vulnerabilidade acerca da variável em questão. Esse fato pode ser explicado pelo envelhecimento da população brasileira, com aumento dos indivíduos em idade ativa fora do mercado de trabalho.

Uma questão que pode surgir a partir do resultado observado está atrelada à estrutura do mercado de trabalho, no qual atualmente é notória a maior exigência no processo de capacitação e qualificação dos trabalhadores, requisito para a ocupação de postos de trabalho. A parcela da população que não dispõe de meios para obter a qualificação demandada, acaba por ter maiores dificuldades no acesso ao mercado de trabalho, mesmo que concomitantemente a oferta de empregos aumente.

Esses indicadores também foram obtidos, desagregando o Paraná em região metropolitana, urbana (não metropolitana), conforme a Tabela 2. Foi possível observar a existência de significativas diferenças no grau de vulnerabilidades. Na região metropolitana, a pobreza é menor do que o verificado para as regiões urbana (não metropolitana) e rural. Na região urbana (não metropolitana), é onde os resultados ficaram mais próximos ao obtido para o Paraná. Já na região rural, tanto em 1995 quanto em 2009, o indicador foi mais elevado. 
Para as três regiões, houve uma redução no indicador total, sendo esta mais expressiva na região rural, 32,3\%. Entretanto, o indicador para essa região em 2009 é sensivelmente maior do que nas demais. Assim, torna-se válido enfatizar que os contextos são distintos nos espaços rural e metropolitano, bem como no urbano não metropolitano, requerendo a proposição de medidas distintas para aliviar as situações de pobreza nesses locais.

Em uma análise geral por dimensão, tem-se que a maior vulnerabilidade está na dimensão “demografia”, com exceção da região rural, em que a maior vulnerabilidade encontra-se na dimensão "saneamento", tanto para 1995 quanto para 2009.

TABELA 2. INDICADORES MULTIDIMENSIONAIS DE POBREZA NAS REGIÕES METROPOLITANA, URBANA E RURAL DO PARANÁ, 1995 E 2009

\begin{tabular}{|c|c|c|c|c|c|c|}
\hline & \multicolumn{2}{|c|}{ Metropolitana } & \multicolumn{2}{|c|}{ Urbana } & \multicolumn{2}{|c|}{ Rural } \\
\hline & 1995 & 2009 & 1995 & 2009 & 1995 & 2009 \\
\hline Total & 0,2123 & 0,1553 & 0,2532 & 0,1760 & 0,3910 & 0,2646 \\
\hline Dimensão 1: Habitação & 0,1486 & 0,1055 & 0,1711 & 0,1216 & 0,2961 & 0,1734 \\
\hline Abrigabilidade & 0,1713 & 0,1114 & 0,2153 & 0,1165 & 0,4150 & 0,2982 \\
\hline Propriedade & 0,2477 & 0,2476 & 0,2924 & 0,2993 & 0,3742 & 0,2885 \\
\hline Energia elétrica & 0,0069 & 0,0000 & 0,0155 & 0,0019 & 0,1726 & o,0292 \\
\hline Déficit habitacional & 0,1686 & 0,0628 & 0,1613 & 0,0689 & 0,2226 & 0,0778 \\
\hline Dimensão 2: Saneamento & 0,1413 & 0,0451 & 0,2126 & 0,0969 & 0,5224 & 0,3707 \\
\hline Esgotamento sanitário & 0,4325 & 0,1513 & 0,7191 & 0,3724 & 0,8024 & 0,6289 \\
\hline Abastecimento de água & 0,0426 & 0,0091 & 0,0518 & 0,0042 & 0,2740 & 0,0664 \\
\hline Coleta de lixo & 0,0644 & 0,0156 & 0,0603 & 0,0068 & 0,8867 & 0,7342 \\
\hline Condição sanitária & 0,0255 & 0,0042 & 0,0191 & 0,0042 & 0,1265 & 0,0535 \\
\hline Dimensão 3: Educação & 0,2094 & 0,1350 & 0,2508 & 0,1653 & 0,3411 & 0,2488 \\
\hline Analfabeto & 0,1415 & 0,0709 & 0,2317 & 0,1356 & 0,3426 & 0,2739 \\
\hline Acesso à escola & 0,4729 & 0,3721 & 0,5374 & 0,4259 & 0,6557 & 0,5932 \\
\hline Escolaridade & 0,0369 & 0,0103 & 0,0470 & 0,0055 & 0,1120 & 0,0162 \\
\hline Progresso escolar & 0,1864 & 0,0869 & 0,1870 & 0,0941 & 0,2543 & 0,1118 \\
\hline Dimnesão 4: Trabalho & 0,2313 & 0,2244 & 0,2616 & 0,2376 & 0,3360 & 0,3220 \\
\hline Qualidade & 0,5095 & 0,4720 & 0,5879 & 0,4859 & 0,8841 & 0,8023 \\
\hline Disponibilidade & 0,1816 & 0,1996 & 0,1896 & 0,2265 & 0,0632 & 0,1524 \\
\hline Trabalho precoce & 0,0028 & 0,0015 & 0,0071 & 0,0003 & 0,0606 & 0,0113 \\
\hline Dimensão 5: Renda & 0,1003 & 0,0589 & 0,1848 & 0,0665 & 0,3696 & 0,1305 \\
\hline Extrema pobreza & 0,0462 & 0,0293 & 0,0961 & 0,0298 & 0,2292 & 0,0648 \\
\hline Pobreza & 0,1544 & 0,0884 & 0,2734 & 0,1032 & 0,5099 & 0,1961 \\
\hline Dimensão 6: Demografia & 0,4426 & 0,3631 & 0,4386 & 0,3682 & 0,4809 & 0,3420 \\
\hline Razão de dependentes & 0,4426 & 0,3631 & 0,4386 & 0,3682 & 0,4809 & 0,3420 \\
\hline
\end{tabular}

FONTE: elaborado a partir das informações da PNAD. 
Em uma análise particular, observa-se que o componente qualidade, representado pela variável "ausência de ocupado no setor formal", constituise em uma das principais preocupações, tanto em 1995 quanto em 2009, nas regiões metropolitana e urbana, com proporções de 47,2\% e 48,6\%, respectivamente, no último ano.

A região urbana apresenta semelhança na ordem das maiores vulnerabilidades, em comparação à região metropolitana, especialmente nos indicadores para a dimensão trabalho e educação. Nota-se que a região urbana tem maior vulnerabilidade nas dimensões analisadas, com exceção da dimensão renda, em 1995, quando tem melhores condições.

Vale destacar que a variável "esgotamento sanitário inadequado", pertencente à dimensão saneamento, constituiu-se na maior vulnerabilidade após a variável "ausência de ocupado no setor formal", em 1995, mas apresentou melhora no ano de 2009. Destaca-se também a "variável ausência de ocupado no setor formal”, em 2009, onde o indicador fora de 80,2\% na região rural. Esse resultado suscita a necessidade de orientação de políticas com maior eficácia no atendimento das questões relacionadas à estrutura do mercado de trabalho, especialmente no que concerne à ampliação da participação dos indivíduos no mercado de trabalho formal, que deve estar associado a melhorias na dimensão da educação.

\section{Considerações finais}

A temática pobreza se constitui em uma desafiante área de estudo das Ciências Econômicas por envolver um alto grau de complexidade, a partir da hipótese do que é uma situação em que uma determinada população não carece apenas de um determinado nível de renda, como expressa significativa parte dos trabalhos desenvolvidos na área, mas sim de um conjunto de condições básicas que garantem a subsistência da coletividade de forma minimamente digna. Sob o enfoque da multidimensionalidade da pobreza, ou seja, do direcionamento para esta conceituação mais ampla, que não se restringe apenas ao nível de renda, fora desenvolvido o presente trabalho, com o objetivo principal de identificar as diversas carências em que incorrem os domicílios paranaenses entre 1995 e 2009.

Os resultados obtidos a partir do indicador multidimensional de pobreza revelaram uma proporção significativa de pobres entre a população paranaense, de 27,9\%, em 1995, e 20,4\%, em 2009. Verificou-se que nas seis dimensões analisadas (condições habitacionais, saneamento, educação, trabalho, renda e demografia) ocorreram avanços, reduzindo o grau de vulnerabilidade dos domicílios paranaenses. 
Apesar dos avanços, destaca-se o aumento da proporção de domicílios em que menos da metade dos membros em idade ativa se encontram ocupados. Isso suscita a necessidade de se implementar políticas que ampliem as chances de inclusão dessa população no mercado de trabalho, especialmente por meio de investimentos em capacitação profissional.

Para as análises isoladas das regiões metropolitana, urbana e rural o nível de pobreza foi mais intenso na região rural, onde os indicadores foram sensivelmente maiores. Por outro lado, essa situação é menos grave na Região Metropolitana de Curitiba.

Assim, a incorporação de outras dimensões, além da renda, para caracterizar e compreender a pobreza como reunião de privações, carências e vulnerabilidades, é relevante no sentido de identificar possíveis soluções a fim de que a população não apenas deixe essa condição, mas sobretudo mantenha-se afastada dessa situação. Daí remete-se ao papel das políticas sociais e econômicas conjugadas, no que concerne à busca da superação da pobreza.

\section{Referências}

ALKIRE, S.; FOSTER, J. (2009). "Counting and Multidimensional Poverty Measurement.” OPHI, Working Paper no 32. URL [on-line]: <http://www3. qeh.ox.ac.uk/pdf/ophiwp/OPHIwp32.pdf>. Acesso em: jul. de 2010.

ANDRADE, T. A. (1993). "Poverty and Public Utilities Pricing”. Texto para Discussão, n. ${ }^{\circ}$ 308. Rio de Janeiro: IPEA.

ATKINSON, A. (2003). Multidimensional Deprivation: Contrasting social welfare and counting approaches. Journal of Economic Inequality 1: 51-65.

BARROS, R. P.; CARVAlHO, M. de; FRANCO, S. (2003). "O Índice de Desenvolvimento da Família (IDF)”. Texto para Discussão, n. ${ }^{\circ} 986$. Rio de Janeiro: IPEA.

BOURGUIGNON, F.; CHAKRAVARTY, S. A. (1999). Family of Multidimensional Poverty Measures. In D.J. Slottje ed. Advances in Econometrics, Income Distribution and Methodology of Science. Essays in Honor of C. Dagum, Springer-Verlag, London.

BOURGUIGNON, F.; CHAKRAVARTY, S. (2002a). Multi-Dimensional Poverty orderings. Calcutta: Indian Statistical Institute.

BOURGUIGNON, F.; CHAKRAVARTY, S. (2002b). The Measurement of Multidimensional Poverty. Journal of Economic Inequality, vol 1, p. 25-49.

CHAKRAVARTY, S.; MUKHERJEE, D; RANADE, R. (1998). On the Family of Subgroup and Factor Decomposable Measures of Multidimensional Poverty, Research on Economic Inequality 8, 175-94.

COMIM, F.; BAGOLIN, I. P .(2002). “Aspectos Qualitativos da Pobreza no Rio Grande do Sul.” Ensaios FEE, vol. 23 (n. ${ }^{\circ}$ especial): p. 467-490. 
DIEESE (Departamento Intersindical de Estatística e Estudos Socioeconômicos). (2010). "Política de valorização do salário mínimo: considerações sobre o valor a vigorar a partir de $1^{\circ}$ de janeiro de 2010”. Nota Técnica, n. ${ }^{\circ} 86$.

DUCLOS, J.; SAHN, D; YOUNGER, S. (2003). Robust Multidimensional Poverty Comparisons. Québec: Universit Laval.

FIGUEIREDO, I. M. Z. (2003). "A Universalização do Ensino Fundamental como Resultado do Processo de Construção da Centralidade da Educação Básica.” Seminário Nacional Estado e Políticas Sociais no Brasil, Cascavel. Anais Seminário Nacional Estado e Políticas Sociais no Brasil. Núcleo de Inovações Tecnológicas (NIT), vol. 01; p. 01-15.

FUSCO, A. (2003). "On the Definition and Measurement of Poverty: The Contribution of Multidimensional Analysis”. 3rd Conference On The Capability Approach: From Sustainable Development To Sustainable Freedom. University of Pavia.

HOFFMANN, R. (1998). Distribuição de renda-Medidas de desigualdade e pobreza. São Paulo: Editora da Universidade de São Paulo, 275p.

IETS - Instituto de Estudos do Trabalho e Sociedade. (2001). Tabulações da PNAD Metodologia na determinação das linhas de pobreza. Rio de Janeiro.

IIETS (Instituto de Estudos do Trabalho e Sociedade). (Vários anos). Base de dados e tabulações. URL [on-line]: http://www.iets.org.br/. Acesso em: set. de 2010.

IPARDES (Instituto Paranaense de Desenvolvimento Econômico e Social). (Vários anos). "Indicadores Socioeconômicos Paraná e RMC.” URL [on-line]: <http:// www.ipardes.pr.gov.br/>. Acesso em: nov. de 2010.

IPEA (Instituto de Pesquisa Econômica e Aplicada). (2001). Metodologia na determinação das linhas de pobreza e indigência. Rio de Janeiro.

IPEADATA (Instituto de Pesquisa Econômica e Aplicada). (Vários anos). Base de dados estatísticos. URL [on-line]: <http://www.ipeadata.gov.br/>. Acesso em: set. de 2010.

KAGEYAMA, A.; HOFFMANN, R. (2006). "Pobreza no Brasil: uma perspectiva multidimensional.” Economia e Sociedade, vol. 15 (1); p. 79-112.

LOPES, H. M.; MACEDO, P.B.R.; MACHADO, A.F. (2005). "Análise de pobreza com indicadores multidimensionais: uma aplicação para Brasil e Minas Gerais.” Revista de Economia Contemporânea, vol. 9(1); p. 125-152.

MUNHOZ, J. P. (2009). Indicadores de Pobreza: limites e potenciais na mensuração da pobreza no Paraná. [Dissertação de mestrado]. Universidade Federal do Paraná (UFPR), 189 p.

NEDER, H. D. (2008). "Um Estudo sobre a Pobreza Rural com Abordagem Multivariada." Congresso da Sociedade Brasileira de Economia e Sociologia Rural (Sober)", Rio Branco, AC. URL [on-line]: <http://www.sober.org.br/ palestra/9/633.pdf>. Acesso em: jul. 2010.

NÓBREGA, W. (2008). Mapeamentos da pobreza sob critérios unidimensional e multidimensional para os estados do Paraná e Sergipe. [Tese de doutorado]. Universidade Federal do Paraná (UFPR), 273 p.

SECRETARIA DO PLANEJAMENTO E COORDENAÇÃO GERAL (2008). Plano Plurianual (PPA 2008-2011). URL [on-line]: < http://www.sepl.pr.gov.br/ modules/conteudo/conteudo.php?conteudo=17>. 
RESENDE, D. C. (2007). Elementos decisivos na construção da posição e prática política de Roberto Requião de Mello e Silva. [Dissertação de mestrado], Universidade Federal do Paraná (UFPR), 165 p.

RIPSA (Rede Interagencial de Informações Para a Saúde). (Vários anos). Indicadores e Dados Básicos Brasil. URL [on-line]: <http://tabnet.datasus.gov.br/cgi/ deftohtm.exe?idb2009/f18.def>. Acesso em: dez. de 2010.

ROCHA, S. (2003). Pobreza no Brasil, afinal do que se trata? Rio de Janeiro: FGV.

SALAMA, P.; DESTREMAU, B. (1999). O tamanho da pobreza: economia política da distribuição de renda. Rio de Janeiro: Garamond.

SEN, A. K. (1976). "Poverty: an ordinal approach to measurement." Econometrica, vol. 44 (2); p. 219-231.

SEN. A. K. (2000). Desenvolvimento como Liberdade. Trad.: Laura Teixeira Motta. São Paulo: Companhia das Letras.

TSUI, K. (2002). Multidimensional Poverty Indices. Shatin: Chinese University of Hong Kong.

Recebido em: 22 de março de 2012

Aceito em: 27 de novembro de 2012 